\title{
O ESTUDO DE REPRESENTAÇÕES PUBLICITÁRIAS SOB UMA \\ PERSPECTIVA HISTÓRICA: DESAFIOS E APONTAMENTOS \\ METODOLÓGICOS
}

The study of representations in advertisement from a historical perspective:

challenges and methodological notes

\section{El estudio de las representaciones de la publicidad desde una perspectiva histórica: retos y notas metodológicas}

Henrique Mazetti ${ }^{1}$

\begin{abstract}
Resumo
O objetivo do trabalho é refletir sobre as opções e os desafios metodológicos envolvidos em pesquisas que se propõem a elaborar análises das representações publicitárias sob uma perspectiva histórica. Inicialmente, são identificados alguns dos protocolos metodológicos tipicamente empregados no estudo da publicidade e também em sua interface com a história. Em seguida, discute-se possibilidade de articulação de métodos quantitativos e qualitativos na pesquisa sobre publicidade. $\mathrm{O}$ artigo se encerra com algumas considerações acerca dos potenciais e dos limites da proposta metodológica apresentada.
\end{abstract}

Palavras-chaves: representações publicitárias, transformações históricas, métodos de pesquisa

\section{Abstract}

The aim of this paper is to discuss the methodological options and challenges involved in researches that propose to develop analysis of representations in advertisements from a historical perspective. Initially, some of the methodological protocols typically employed in the study of advertising and in its interface with history are identified. Then, we discuss the possible articulations of quantitative and qualitative methods in

\footnotetext{
${ }^{1}$ Professor do Departamento de Comunicação Social da UFV. Mestre e Doutor em Comunicação e Cultura pela ECO/UFRJ. Email: mazetti@ufv.br. Telefone: (31) 3899-4502. Endereço: Departamento de Comunicação Social - UFV. Avenida Peter Henry Rolfs, s/n - Campus Universitário, Viçosa - MG, 36570-900JUN
} 
O estudo de representações publicitárias sob uma perspectiva histórica: desafios e apontamentos metodológicos

de Henrique Mazetti

research on advertising. The article concludes with some considerations about the potential and limits of the methodological proposal.

Keywords: advertising representations, historical transformations, research methods

\section{Resumen}

El objetivo de este trabajo es discutir las opciones y desafíos metodológicos implicados en la investigación que pretende preparar análisis de las representaciones de publicidad desde una perspectiva histórica. Inicialmente, se identificaron algunos de los protocolos metodológicos normalmente empleadas en el estudio de la publicidad y en su interrelación con la historia. A continuación, se discute la posibilidad de métodos cuantitativos y cualitativos en la investigación de la publicidad. El artículo concluye con algunas consideraciones sobre el potencial y los límites de la propuesta metodológica presentada.

Palabras-clave: representaciones de la publicidade, transformaciones históricas, métodos de investigación.

\section{INTRODUÇÃO}

Em contribuição ao debate sobre as metodologias adotadas em pesquisas de comunicação, Braga (2011) sublinha a importância da adoção de um caráter reflexivo, dinâmico e processual para o desenvolvimento metodológico. Contra a aplicação de modelos pré-estabelecidos e fechados de investigação, o autor salienta as particularidades de cada trabalho e a maneira como elas exigem criatividade e invenção no terreno da escolha dos métodos - o que não significa abonar a ausência de rigor ou a falta de sistematização. Com perspicácia, Braga define a metodologia como um percurso composto por contínuas tomadas de decisão referentes ao encaminhamento da pesquisa: um frequente alinhavar, testar, desfazer e repensar as relações entre o objeto de estudo escolhido, sua observação sistemática mediante os problemas de pesquisa propostos e as referências teóricas acionadas.

A reflexão sobre os métodos adotados em uma investigação não deve ser vista, portanto, como uma simples obrigatoriedade burocrática, nem pode ser resumida a um gesto ensaiado de deferência consentida a protocolos metodológicos prontos. Ao contrário, pensar a metodologia de pesquisa se torna um constante avaliar dos entraves e 
O estudo de representações publicitárias sob uma perspectiva histórica: desafios e apontamentos metodológicos

de Henrique Mazetti

soluções encontradas para os mais diferentes desafios de cada investigação. Nas palavras de Braga (2008:8): “o abandono da injunção determinante do 'a fazer' impõe maior atenção e cuidados quanto ao 'em fazendo'. Nessa perspectiva, a metodologia é uma sabedoria na tomada de decisões em que o pesquisador se vê constantemente envolvido".

A concepção de metodologia de Braga, longe de ser dissonante no atual cenário acadêmico, encontra inúmeros interlocutores na área de comunicação. Entre eles Lopes (2004), que descreve a escolha dos métodos e das técnicas de investigação como uma "aventura" e não um receituário ou uma fórmula apriorística de "como fazer" pesquisa. Entretanto, no elusivo campo de estudos acadêmicos dos fenômenos publicitários, as experimentações metodológicas, ainda que existentes, são silenciosas e marginais, enquanto modelos de pesquisa consagrados continuam ditando a abordagem das manifestações publicitárias.

O objetivo do presente trabalho é refletir sobre as opções e os desafios metodológicos envolvidos em pesquisas que se propõem a elaborar análises das representações publicitárias sob uma perspectiva histórica. Este artigo condensa observações e experiências decorrentes do desenvolvimento da pesquisa que originou minha tese de doutorado, que aborda as transformações históricas das representações de felicidade e boa vida no discurso publicitário dos últimos cinquenta anos. Inicialmente, são identificados alguns dos protocolos metodológicos tipicamente empregados no estudo da publicidade e também em sua interface com a história. Em seguida, discute-se possibilidade de articulação de métodos quantitativos e qualitativos na pesquisa sobre publicidade. $\mathrm{O}$ artigo se encerra com algumas considerações acerca dos potenciais e dos limites da proposta metodológica apresentada.

\section{MÉTODOS DE PESQUISA NA PUBLICIDADE}

Em um levantamento feito a partir da observação de teses e dissertações publicadas nos anos 1990, Jacks (2001) concluiu que, entre os 1789 trabalhos averiguados, apenas 59 apresentavam a publicidade como objeto de estudo. Ao lado da relativa escassez de interesse da área sobre o tema, destacava-se a pobreza do instrumental teórico-metodológico empregado nas investigações que abordavam o fenômeno publicitário. De acordo com a autora, as pesquisas que se preocupavam com a 
O estudo de representações publicitárias sob uma perspectiva histórica: desafios e apontamentos metodológicos

de Henrique Mazetti

publicidade eram orientadas por problematizações frágeis e pouco imaginativas, incapazes de articular a comunicação com outras disciplinas ou de levantar indagações sobre o objeto que respondessem às necessidades sociais e culturais do momento. Jacks relata que as pesquisas sobre publicidade nos anos 1990 "moviam-se prioritariamente em torno do estudo da linguagem em si mesma, através de análises formais que não avançam na articulação com outras instâncias sociais" (2001:211).

Investigações mais atuais do estado da arte das pesquisas sobre publicidade na área de comunicação mostrem alguns avanços no que tange aos modelos analíticos empregados no entendimento dos processos de produção e recepção das mensagens publicitárias (Jacks et al. 2010, Zozolli 2010). Todavia, a ênfase nas análises formais da linguagem publicitária continua a embasar boa parte das investigações sobre o tema. Numerosas pesquisas são informadas por diferentes vertentes da análise de discurso, da semiótica ou de outros modelos teórico-metodológicos oriundos especialmente da linguística. Inclusive pesquisas cujas questões centrais não passam, contraditoriamente, pela interrogação acerca estruturas de linguagem empregadas pelos anúncios.

Vale assinalar que o exame formal de anúncios isolados ou do discurso publicitário como gênero discursivo, ainda que de extrema importância, responde a um conjunto específico e delimitado de problemas de pesquisa. A tendência a se estudar a publicidade com um foco na linguagem em si mesma acaba por obscurecer outras formas de abordar o fenômeno. Como afirma Jacks, "com isto apenas há uma troca de objeto de estudo ratificando indefinidamente aspectos já detectados em outras pesquisas" (Jacks 2001: 211).

Uma das limitações da abordagem "estruturalista" da publicidade é a sua dificuldade em fornecer ferramentas para a elaboração de questionamentos sobre as transformações históricas do discurso publicitário. Um exemplo é Decoding Advertisements, de Judith Williamson (1978), considerado um dos trabalhos pioneiros na aplicação da semiologia de Barthes $(2001,2007)$ na análise de anúncios comerciais. Interessada em desvendar as artimanhas ideológicas utilizadas na publicidade, a autora tornou visível uma série de operações associativas, justaposições de significantes e significados e diversas outras estratégias discursivas que permitiam à publicidade construir sistemas de significação que apresentam os argumentos de venda como naturais, evidentes e inevitáveis. 
O estudo de representações publicitárias sob uma perspectiva histórica: desafios e apontamentos metodológicos

de Henrique Mazetti

Ainda assim, é Williamson (1978: 99) quem sublinha que o desvendamento da "metaestrutura" dos anúncios nada informa sobre suas implicações sociais ou históricas. O foco na linguagem esclarece as lógicas internas da mensagem publicitária. Explica como a publicidade "cozinha" a realidade "crua", segundo sugere a metáfora de LéviStrauss, mas é incapaz de avaliar o contexto cultural em que o processo se dá. Em outras palavras, a análise estruturalista da publicidade pode traçar em ricos detalhes as formas arquitetônicas através das quais as mensagens publicitárias são construídas, mas ela pouco informa sobre o movediço terreno sociocultural no qual os anúncios são elaborados.

Contra o formalismo da análise da linguagem, que atrofia os momentos de produção e consumo dos anúncios publicitários, Rocha (1995) defende o emprego das técnicas de pesquisa etnográfica - que o autor acredita remediar ainda o subjetivismo das análises textuais. Já Piedras (2009), avançando a noção de "fluxo publicitário" inspirada nas ideias de Raymond Williams sobre a televisão, enfatiza de modo semelhante os estudos de recepção. Perguntar o que fazemos com a publicidade, ao invés de indagar o que ela faz conosco, parece ser, como em outras esferas de investigação dos processos comunicacionais, a ordem do dia (Silverstone 2002).

Todavia, as inquirições sobre as audiências não permitem estudos longitudinais da publicidade e tendem a relativizar as determinações impressas nos artefatos midiáticos no momento de sua produção. Não apenas se torna problemático interrogar o discurso publicitário a partir de uma perspectiva histórica (aplicar a etnografia a um anúncio dos anos 1960 é teoricamente possível, mas praticamente inviável). Perde-se de vista também a capacidade de averiguar como a publicidade oferece mapas interpretativos particulares do cotidiano social, uma vez que as análises de recepção tendem a privilegiar a variabilidade de interpretações dos textos midiáticos. As múltiplas possibilidades de decodificação do discurso publicitário por parte do público são valorizadas, enquanto os processos de codificação - de transformação do real em discurso - tornam-se secundários.

É preciso voltar ao texto, portanto, caso a intenção seja estudar as transformações históricas nas representações publicitárias. Desta vez, porém, não mais como simples fenômenos de linguagem, mas objetivações de uma série de práticas determinadas: registros de momentos particulares, documentos de certos valores e crenças, arquivos de ideias, imagens e aspirações marcadas pelo seu contexto. Assim, a 
O estudo de representações publicitárias sob uma perspectiva histórica: desafios e apontamentos metodológicos

de Henrique Mazetti

interpretação dos anúncios exige procedimentos que extrapolam, mas levam em consideração, as observações sobre o uso da linguagem na publicidade.

Neste artigo, abordo alguns esquemas metodológicos que servem de base para as opções tomadas na seleção e na observação do material analisado em pesquisas que problematizam as transformações históricas das representações publicitárias. A intenção não é reivindicar a construção de critérios estritamente objetivos, mas explicitar um caminho de investigação possível na tentativa de analisar como as imagens e textos veiculados nas páginas publicitárias de veículos impressos se alteram e o que tais mudanças podem nos dizer sobre a sociedade que produz tais discursos.

Ao contrário do trabalho de Williamson (1978), não está em foco a problematização das estratégias de persuasão publicitária, mas as mudanças nas imagens socialmente sancionadas utilizadas pela publicidade para atrair e convencer o público. Parte-se da premissa, já estabelecida em diversos trabalhos (Lears 1983; 1994; Leiss, Kline e Jhally 1990; Marchand 1985; Rocha 1990; 1995; 2006; Schudson 1984) de que os anúncios publicitários revestem os produtos de significados culturais mediante conselhos, encorajamentos, precauções, promessas e ameaças enviesadas acerca de como o indivíduo deve se relacionar consigo mesmo e com os outros no universo social. Ao interrogar as transformações nas representações publicitárias, portanto, pode-se observar alterações na moralidade e nos valores sociais considerados legítimos e explicitados nos anúncios publicitários. Mudanças resultantes de uma série de contingências, que não podem ser resumidas às simples volições do campo profissional publicitário ou aos interesses de classe dos anunciantes e donos de agências.

Uma vez que tal proposta se aproxima da história, convém procurar na disciplina alguns possíveis caminhos para a interpretação do discurso publicitário. Sant'anna (1997) observa que, no final da década de 1990, a publicidade se tornou um objeto de interrogação legítimo para os historiadores. Todavia, questões de método ainda se insinuam sobre o tema, especificamente em relação às análises dos textos e imagens publicitárias. Após defender que a publicidade se desenvolve no interior da história, e por isso merece ser investigada, a autora traça algumas breves considerações sobre o caráter fugidio dos anúncios, o que gera dificuldades analíticas.

Verbalmente, as mensagens comerciais podem exibir, ao mesmo tempo, arcaísmos culturais e inquietações morais agudamente contemporâneas. Elas não 
O estudo de representações publicitárias sob uma perspectiva histórica: desafios e apontamentos metodológicos

de Henrique Mazetti

possuem necessariamente uma coerência interna, nem formam um discurso único, sem saliências ou contradições. Visualmente, os anúncios podem ser interpretados como "experiências históricas", condicionadas não só por percepções e recepções culturais historicamente determinadas, mas pelo próprio desenvolvimento do aparato técnico responsável pela produção das mensagens. Desse modo, a historiadora afirma que "o uso da publicidade como fonte de estudos requer a compreensão de outras histórias que a integram e a ultrapassam" (Sant'anna 1997:98), como a história da imprensa, da fotografia etc.

Sant'anna elenca, então, uma variedade de opções metodológicas para analisar as imagens publicitárias, sem se filiar especificamente a qualquer uma delas. Para demonstrar a lenta substituição das referências à dor, ao sofrimento e à morte nos anúncios do final do século XIX por celebrações do corpo sadio e do prazer a partir das décadas de 1920 e 1930, a autora recorre implicitamente à análise de discurso foucaultiana ${ }^{2}$, ainda que não esclareça como procurou sistematizar a interpretação dos anúncios. Ao invés disso, a pesquisadora se ampara ainda em Foucault para observar que sua intenção é sublinhar a singularidade histórica de diferentes momentos, que seriam caracterizados por distintas liberdades e coações.

A ausência de indicações mais concretas sobre como organizar as observações dos anúncios em uma perspectiva histórica também é percebida em trabalhos consagrados como os de Lears (1994) e Marchand (1985). Lears nota sucintamente que sua análise dos anúncios e das revistas do campo publicitário é guiada por interesses subjetivos e, desembaraçado, isenta-se das imposições de imparcialidade "científica". Já Marchand se orgulha de relatar que reuniu em sua investigação mais de 18 mil anúncios das primeiras décadas do século $\mathrm{XX}$, mas não descreve como processou o volumoso material coletado, ainda que fique claro ao longo do seu trabalho que a intenção era encontrar padrões argumentativos e recorrências temáticas capazes de demonstrar como a publicidade orientava os indivíduos a se adequar às exigências da vida moderna.

\section{ARTICULANDO O QUANTITATIVO E O QUALITATIVO}

\footnotetext{
${ }^{2}$ Sant'anna (1997) não utiliza tal expressão. Contudo, a perspectiva foucaultiana se apresenta no trabalho de Sant'anna principalmente a partir de um modo particular de fazer história, que Veyne (1998) descreve como o abandono da busca de uma única explicação causal para os acontecimentos, em direção à tentativa de compreender suas singularidades, as múltiplas condições que os possibilitam.
} 
O estudo de representações publicitárias sob uma perspectiva histórica: desafios e apontamentos metodológicos

de Henrique Mazetti

Observações mais concretas sobre possíveis caminhos metodológicos são encontradas em trabalhos desenvolvidos na comunicação que aplicam um olhar histórico e cultural para a publicidade. Dois estudos elaborados coletivamente, um a partir da publicidade canadense (Leiss, Kline e Jhally 1990) e outro sobre os anúncios na Inglaterra (Richards, Botteril e Macrury 2000), oferecem sugestões valiosas para o tratamento e a interpretação das mensagens publicitárias. Ambos possuem objetivos ambiciosos: cartografar os principais temas, abordagens e estratégias persuasivas da publicidade ao longo do século XX, a fim de elaborar periodizações que permitam compreender as cambiantes relações entre a publicidade, a cultura de consumo e a sociedade moderna.

Leiss, Kline e Jhally (1990) avaliam os limites e potencialidades daquelas que acreditam ser as duas principais abordagens metodológicas empregadas para o estudo dos anúncios publicitários, a semiologia e a análise de conteúdo. A primeira, exemplificada pelos variados estudos de Barthes (2001), Williamson (1978), Dyer (1982) e Goffman (1979), teria a seu favor a capacidade de examinar detidamente os códigos culturais acionados pela publicidade e a maneira como eles são atualizados a partir de referentes localizados em sistemas culturais específicos. A semiologia permitiria ainda desnudar as múltiplas camadas de sentido denotativo e conotativo das mensagens comerciais: o que um anúncio sugere explícita e implicitamente através de referências verbais e visuais imediatas ou transferências internas e externas entre os signos.

Os autores salientam, porém, que a eficácia do método semiológico dependeria essencialmente da habilidade do analista em alcançar os níveis mais profundos de construção de sentido dos anúncios. Além disso, a abordagem tenderia a enumerar infinitamente os códigos utilizados em cada anúncio particular, o que dificultaria seu emprego para organizar a análise de um grande número de mensagens. Mais importante, talvez, a semiologia não se aplicaria a qualquer tipo de anúncio, mas necessitaria de exemplos específicos (tipos-ideais) para confirmar suas teorias linguísticas. Assim, o que seria um método para interpretar o discurso publicitário se transformaria, muitas vezes, em uma estratégia que utiliza as mensagens comerciais para exemplificar certos usos da linguagem. Um processo que alimenta o circuito analítico autocomprobatório que Jacks (2001) criticava. 
O estudo de representações publicitárias sob uma perspectiva histórica: desafios e apontamentos metodológicos

de Henrique Mazetti

Por sua vez, a análise de conteúdo responderia, segundo Leiss, Kline e Jhally (1990), às principais deficiências da abordagem semiológica, sendo capaz de lidar com amostragens de anúncios arbitrárias e de maior alcance numérico, a partir do estabelecimento de categorias analíticas objetivas, exaustivas, mutualmente exclusivas e limitadas. Tal abordagem poderia quantificar de maneira mais precisa padrões de similaridade e diferença entre os anúncios veiculados ao longo de grandes períodos, possibilitando ao pesquisador ultrapassar o diagnóstico impressionista da "relativa preponderância" de uma determinada tendência no imaginário construído pelo discurso publicitário ao longo do tempo. Munido de um protocolo de codificação previamente testado, o analista seria capaz de identificar estatisticamente, por exemplo, a proeminência de certos temas em diferentes etapas da história da publicidade.

Entretanto, a lógica positivista na qual se assentam as pesquisas de caráter quantitativo tem sido severamente criticada no que tange à sua adequação às investigações desenvolvidas nas ciências humanas e sociais. Leiss e seus companheiros observam, sobretudo, as dificuldades de lidar com a produção de sentido em termos estatísticos. Enquanto a análise de conteúdo pode fornecer respostas objetivas a respeito dos elementos manifestos dos anúncios, a sua capacidade interpretativa se restringe a um raio diminuto de aplicação. Ela garante um método de organização dos dados, mas ao mesmo tempo corre o risco de "achatar" o material analisado em nome do rigor metodológico.

A solução encontrada pelos autores para identificar mudanças periódicas nos anúncios publicitários é combinar estratégias quantitativas e qualitativas, de modo a conjugar a capacidade de sistematização da análise de conteúdo com as potencialidades interpretativas da abordagem semiológica. Tal arranjo é operacionalizado a partir da construção de categorias analíticas que não se baseiam simplesmente nos elementos superficiais dos anúncios, mas que incorporam os códigos utilizados pelo discurso publicitário e visam tornar as representações publicitárias em dados quantificáveis.

Assim, Leiss, Kline e Jhally (1990: 228-284) separam as formas de codificação utilizadas na publicidade em diferentes instâncias, como estilo (humor, narrativa, design), apelo (racional, emocional, testemunhal), valores (qualidade do produto, lazer, progresso, individualismo), temas (utilidades do produto, associações do bem de consumo com o consumidor e outras formas de vinculação da mercadoria à vida cotidiana do público), relações entre pessoas e produtos etc. Além disso, os autores 
O estudo de representações publicitárias sob uma perspectiva histórica: desafios e apontamentos metodológicos

de Henrique Mazetti

incorporam ao seu protocolo aferições sobre o emprego dos formatos típicos de anúncios (orientados para o produto, pela imagem, para a personalização da mercadoria e para os estilos de vida dos consumidores). Sobre o método concebido e aplicado, os autores argumentam que, "os resultados dão maior substância e concretude à noção semiológica de código ao combinar a sua sofisticada sensibilidade interpretativa com as estratégias mais específicas, rigorosas e quantitativamente orientadas encontradas na análise de conteúdo" (1990:227).

Todo o esforço analítico dos autores, que tomou mais de cinco anos e envolveu uma grande equipe, possibilitou uma série de tabulações que ilustram diferentes periodizações da publicidade canadense durante todo o século XX. Assim, os pesquisadores enfatizam as sutis transformações que levaram os anúncios, inicialmente focados na transmissão de informações sobre os bens anunciados, a cada vez mais empregar em suas representações os contextos sociais em que o consumo das mercadorias promovidas se dá. Esmiuçando os códigos adotados nas mensagens comerciais, Leiss e seus colegas de pesquisas demonstram como a publicidade procurou educar o público a ler os anúncios, passou a conferir simbolismo às mercadorias, associou segmentos de consumidores a produtos particulares e, finalmente, privilegiou ostensivamente apresentações não utilitárias dos bens, tornando marcas, serviços e objetos anunciados como elementos indissociáveis das dinâmicas de interação social.

Abertamente inspirado na pesquisa de Leiss, Kline e Jhally (1990), o trabalho de Richards, Botteril e MacRury (2000) procura investigar a significância sociocultural da publicidade na Inglaterra na segunda metade do último século. Também aplicando métodos quantitativos e qualitativos, os autores buscam avançar na compreensão das dinâmicas do discurso publicitário ao introduzir uma preocupação mais aguda com o contexto de produção dos anúncios - respondida com entrevistas com profissionais do campo - e um arcabouço teórico formulado para interrogar especificamente as dimensões psicossociais da publicidade. Assim, os autores elaboram categorias analíticas direcionadas pela crença de que os textos e imagens publicitárias "possuem uma relação com as qualidades de autoexperiência, inclusive com os determinantes mais profundos de identidade [...] logo, procuramos evidências relativas à amplitude e ao balanço dos valores que predominam nas negociações de identidades, as qualidades e forças dos vínculos sociais e a natureza das tensões no interior do self” (2000:101). 
O estudo de representações publicitárias sob uma perspectiva histórica: desafios e apontamentos metodológicos

de Henrique Mazetti

Em um esforço que também envolveu um grande número de pesquisadores, Richards e sua equipe classificaram uma amostra de cinco décadas de publicidade impressa e televisiva inglesa em categorias relativas às ansiedades latentes e manifestas exibidas nos anúncios e aos valores práticos, sociais e sensuais associados aos bens em exibição. Focando-se em mensagens de produtos específicos em dois estudos de caso (anúncios de automóveis e de serviços bancários), os autores demonstram como o discurso publicitário constantemente se renova ao oferecer os produtos anunciados como formas de administrar os dilemas da vida cotidiana, ciclicamente se orientando por valores mais práticos, relativos à utilidade dos produtos, ou valores simbólicos, relacionados abstratamente às mercadorias.

Os percursos metodológicos desenvolvidos nos dois trabalhos são profícuos em sugestões para a elaboração dos métodos e técnicas utilizados na pesquisa sobre a publicidade em uma perspectiva histórica. Ainda assim, algumas premissas nas quais eles se baseiam podem ser questionadas, da mesma forma como certas escolhas dos autores não se aplicam aos objetivos ou às possibilidades de trabalhos particulares. $\mathrm{O}$ primeiro ponto que deve ser problematizado é a suposta objetividade da análise quantitativa e sua utilidade para a sistematização dos anúncios analisados. Ainda que Leiss, Kline e Jhally (1990) argumentem que a tabulação estatística dos temas publicitários permita ultrapassar observações subjetivas de "relativa preponderância" de padrões argumentativos no discurso publicitário em direção à aquisição de dados concretos, pode-se contra-argumentar que tais informações não passam de "efeitos de verdade".

Para ilustrar o argumento, apenas em 1973, quando a publicidade brasileira começava a se fortalecer, o Anuário de Propaganda contabilizou que cerca de 13 mil anúncios impressos haviam sido veiculados nos meios de comunicação brasileiros. Além da avultada produção comunicativa, a maioria das mensagens publicitárias foi, e continua sendo, publicada repetidamente, e muitas delas fazem parte de intricadas campanhas, que possuem diversas etapas. Enquanto alguns produtos são apresentados de variadas formas, outros anúncios podem ser veiculados de maneira idêntica durante toda uma década ou até mais. As mensagens publicitárias não só são heterogêneas em seu conteúdo, como também em seus formatos e modos de transmissão.

Supor que seja possível alcançar algum grau de "objetividade” através da análise de conteúdo do discurso publicitário é partir da controversa premissa de que os anúncios 
O estudo de representações publicitárias sob uma perspectiva histórica: desafios e apontamentos metodológicos

de Henrique Mazetti

publicitários possuem uma lógica interna homogênea e não problemática, que simplesmente está à espera de ser desvendada. Entretanto, quando se observa a publicidade ao longo do tempo, é o seu caráter contraditório, irregular e às vezes até mesmo anacrônico que chama a atenção, como observou Sant'anna (1997).

Isso não quer dizer que não existam descontinuidades e permanências no discurso publicitário que possam ser observadas, mas simplesmente que produzir levantamentos estatísticos sobre a publicidade talvez não ultrapasse também a identificação das "relativas preponderâncias". A análise de conteúdo aplicada a interrogações sobre as transformações históricas das representações publicitárias pode muito bem aferir padrões e recorrências que passariam despercebidos de outro modo a um pesquisador. Contudo, a pesquisa quantitativa não pode ser concebida como uma garantia de objetividade ou, pior, um atalho para a verdade: o legítimo labor empírico de comprovar, de uma vez por todas, hipóteses teóricas. Os levantamentos estatísticos também são determinados pelos critérios de amostragem adotados, pelas categorias analíticas elaboradas, pelos quadros teóricos em que se baseiam e pelas perguntas que lançam aos objetos analisados. Em síntese, eles são situados e parciais como qualquer outro método de pesquisa.

O principal benefício da análise de conteúdo não está na "concretude" de seus resultados, mas no processo de sistematização do material analisado. Um dos principais desafios que se apresenta a uma pesquisa de caráter longitudinal, que procura interrogar mudanças no discurso publicitário durante um longo período é como ordenar o avultado número de anúncios disponíveis para investigação. As técnicas de amostragem e classificação possibilitadas pela análise de conteúdo asseguram um relativo rigor na escolha das mensagens a serem observadas e uma bem-vinda forma organização do corpus. A partir daí, porém, uma interpretação mais nuançada dos anúncios a partir das tendências observadas pode ser mais útil do que a elaboração de gráficos sobre os dados levantados.

As propostas de Leiss, Kline e Jhally (1990) e Richards, Botteril e McRury (2000) se baseiam na elaboração de critérios mais complexos para a construção das categorias analíticas empregadas na análise quantitativa dos anúncios publicitários. Ao invés de simplesmente quantificar elementos manifestos dos anúncios, ambos os trabalhos se propõem a criar classificações interpretativas mais específicas com a ajuda da semiologia e de outros quadros teóricos para periodizar a publicidade. Por mais 
O estudo de representações publicitárias sob uma perspectiva histórica: desafios e apontamentos metodológicos

de Henrique Mazetti

qualitativas que almejem, porém, as pesquisas mantêm como orientação principal a tabulação numérica dos anúncios.

Ainda que tal opção seja viável se realizada em uma pesquisa com um número razoável de colaboradores, uma inversão de tal lógica também é promissora: empregar estratégias típicas da pesquisa quantitativa para organizar uma observação primordialmente qualitativa da publicidade. Utilizar algumas estratégias da análise de conteúdo para identificar recorrências e descontinuidades temáticas na construção dos valores e ideais expostos nos anúncios publicitários para, em seguida, interpretá-los com a ajuda de trabalhos teóricos vinculados ao problema de pesquisa desenvolvido.

O caminho desenhado não se destina, portanto, a desvendar um plano mestre que tenha se desenvolvido linearmente no discurso publicitário ou para traçar exaustivamente todas as mudanças nas representações publicitárias. Ao contrário, a intenção é bem mais específica: identificar as alterações contingentes e irregulares nas imagens fornecidas pela publicidade na expectativa de que tal observação contribua para a reflexão sobre as transformações históricas e culturais nas representações publicitárias.

\section{CONSIDERAÇÕES FINAIS}

Após apresentar algumas definições teóricas e possibilidades de escolhas de técnicas específicas para lidar com os anúncios, abordamos, nas considerações finais, algumas premissas metodológicas mais amplas que podem informar pesquisas sobre mudanças históricas no discurso publicitário. A primeira delas está relacionada com o recorte do objeto. Independentemente do volume de material coletado, é importante manter o foco no tema selecionado. Ainda que transformações nas formas de representar, por exemplo, a criança ou a identidade nacional, não estejam completamente dissociadas, elas não necessariamente seguem uma mesma lógica. É possível dizer que o discurso publicitário não possui uma história, mas várias - ou pelos menos variados modos de leitura. Outras histórias podem ser, ou já foram, contadas. A maneira como a publicidade apresenta o prazer, problematiza o corpo, aborda o risco, descreve o consumo, constrói um senso de brasilidade e oferece modelos de feminilidade, masculinidade e juventude, por exemplo. As transformações discursivas da publicidade certamente possuem transversalidades e paralelismos com outros temas 
O estudo de representações publicitárias sob uma perspectiva histórica: desafios e apontamentos metodológicos

de Henrique Mazetti

possíveis. Entretanto, procurar uma grande narrativa ou multiplicar os temas analisados pode impossibilitar uma análise detalhada ou demandar outros tipos de interrogação e interpretação dos anúncios selecionados.

Uma segunda premissa metodológica se relaciona com os sentidos produzidos pelas mensagens comerciais em análise. Desenvolver uma leitura possível dos anúncios publicitários, informada por discussões teóricas pertinentes ao tema escolhido, é o máximo que o pesquisador pode almejar. Diferentes pessoas certamente podem atribuir significados variados aos produtos anunciados, contrariando as molduras interpretativas oferecidas pela publicidade. O produto que um anúncio apresenta como insígnia de distinção social pode ter sido tomado como símbolo de virilidade ou liberação sexual. A mercadoria exposta como instrumento para expressar autenticidade pode significar conformismo às regras sociais para outro leitor. A publicidade tenta fixar os significados dos objetos, mas nem sempre é bem sucedida. Todavia, identificar as determinações discursivas dos anúncios, mesmo tendo consciência de que essas ordens são continuamente ignoradas ou francamente contrariadas pelo público é um trabalho em si valioso.

Além disso, os próprios anúncios estão abertos a múltiplas interpretações. A celebração irrestrita das emoções individuais presente em algumas mensagens pode ser recebida com jocosidade ou nem mesmo ser compreendida por certos leitores. A peça que elenca uma celebridade como protagonista é possivelmente interpretada por seu fã de maneira completamente diferente do sentido dominante de uma mensagem. As missivas nacionalistas ou as inflexões do ideário desenvolvimentista são as similadas de modos diversos, de acordo com as crenças políticas de cada receptor. Em outra dimensão, um pesquisador informado por preocupações teóricas distintas pode chegar a conclusões diferentes dos anúncios abordados. Não é possível defender que as interpretações desenvolvidas em uma pesquisa sejam mais fiéis ou objetivas em relação a um sentido "mais profundo" ou "verdadeiro" dos anúncios. Novamente, contudo, a existência de infinitas possibilidades de interpretação das peças publicitárias não impede a tentativa de identificar padrões e recorrências temáticas nos anúncios.

Uma última consideração das limitações metodológicas diz respeito à capacidade de generalização das observações dos elementos presentes nas peças analisadas. As transformações nos modos de representar do discurso publicitário estão circunscritas à origem do material coletado. Um percurso histórico observado na análise 
O estudo de representações publicitárias sob uma perspectiva histórica: desafios e apontamentos metodológicos

de Henrique Mazetti

dos principais semanários brasileiros pode não ser encontrado em outras publicações, mais segmentadas. Por isso a importância da escolha criteriosa da origem do material a ser analisado. Uma observação correlata se aplica ao suporte. Anúncios de diferentes plataformas, como o impresso e a TV, por exemplo, também podem não apresentar perfeita sintonia, uma vez que cada mídia possui suas próprias lógicas, potenciais e limitações.

Finalmente, as alterações nas representações publicitárias não correspondem, necessariamente, às mudanças nos valores partilhados pela sociedade como um todo ou, especialmente, por grupos específicos. Ao invés de pensar a publicidade como um simples instantâneo da mentalidade de uma época, é mais útil pensar o discurso publicitário como uma força que pretende arregimentar padrões de comportamento e fornecer formas de autocompreensão que podem ou não ser correntes. Em alguns momentos, os anúncios podem até mesmo corresponder supostamente a retratos fiéis dos valores e práticas cotidianas, mas em outros, podem ser tentativas de construir um mundo imaginário ainda a ser vivido, ou então, ainda, de reter transformações em curso e manter um passado já abandonado. Por vezes, a publicidade diz quem nós somos, mas também diz quem nós poderíamos ser ou ainda, de modo saudosista, o que nós éramos. Ainda assim, a publicidade não é autônoma em relação às dinâmicas sociais de onde emerge. Mesmo quando os anúncios não se referem a uma realidade concreta, o imaginário acionado contém aspirações que os publicitários acreditam ser partilhados pelo público, o que garante a relevância da análise histórica do discurso publicitário.

\section{REFERÊNCIAS BIBLIOGRÁFICAS}

BARTHES, R. Mitologias. Rio de Janeiro: Bertrand, 2001. Elementos de semiologia. São Paulo: Cultrix, 2007.

BRAGA, J. L. A prática da pesquisa em Comunicação: abordagem metodológica como tomada de decisões. E-Compós, v. 14, n. 1, p. 1-33, 2011.

JACKS, N. A publicidade vista pela academia: tendências dos anos 90. In: RAMOS, Roberto (org.). Mídia, textos e contextos, p. 205-219. Porto Alegre: PUC-RS, 2001. 
O estudo de representações publicitárias sob uma perspectiva histórica: desafios e apontamentos metodológicos

de Henrique Mazetti

JACKS, N.; PIEDRAS, E.; KNEWITZ, A. P.; MALDANER, N. M. A publicidade vista entre 2000 e 2005: pesquisas com foco na recepção. ECO-PÓS, v. 13, p. 14-28, 2010.

LEARS, T.J. J. Fables of abundance: a cultural history of advertising in America. New York: Basic Books, 1994.

LEISS, W.; KLINE, S.; JHALLY, S. Social communication in advertising: persons, products and images of well-being. Ontario: Nelson Canada, 1990.

LOPES, M. I. V. Pesquisa de comunicação: questões epistemológicas, teóricas e metodológicas. Revista brasileira de ciências da comunicação, v. XXVII, n. 1, p. 13-39, 2004.

MARCHAND, R. Advertising the american dream. Making way for modernity, 19201940. Berkeley: University of California Press, 1985.

PIEDRAS, E. Fluxo publicitário: anúncios, produtores e receptores. Porto Alegre: Sulina, 2009.

PIEDRAS, E.; JACKS, N. A publicidade e o mundo social. Uma articulação pela ótica dos estudos culturais. Contemporânea, v.3, n.2, p. 197-216, 2005.

RICHARDS, B.; MACRURY, I.; BOTTERILL, J. The dynamics of advertising. Reading: Harwood Academic Publishers, 2000.

ROCHA, E. Magia e capitalismo: um estudo antropológico da publicidade. São Paulo: Brasiliense, 1990.

. A sociedade do sonho: comunicação, cultura e consumo. Rio de Janeiro: Mauad, 1995.

- Representações do Consumo: estudos sobre a narrativa publicitária. Rio de Janeiro: PUC-Rio/Mauad, 2006.

SANT'ANNA, D. B. Propaganda e história: antigos problemas, novas questões. Projeto História, n. 14, p. 89-112, 1997.

SCHUDSON, M. Advertising, the uneasy persuasion: its dubious impact on American society. Nova Iorque: Basic Books, 1984.

SEVERIANO, M. F. Narcisismo e publicidade: uma análise psicossocial dos ideais do consumo na contemporaneidade. São Paulo: Annablume, 2001.

SILVERSTONE, R. Por que estudar a mídia?. São Paulo, Edições Loyola, 2002. 
O estudo de representações publicitárias sob uma perspectiva histórica: desafios e apontamentos metodológicos

de Henrique Mazetti

VEYNE, P. Como se escreve a história; Foucault revoluciona a história. Brasília: UNB, 1998.

WILLIAMSON, J. Decoding advertisments: ideology and meaning in advertising. London: Marion Boyars, 2002.

ZOZZOLI, J. C. J. A pesquisa em publicidade e propaganda na INTERCOM. Anais do I Pró-Pesq PP - Encontro nacional de pesquisadores em publicidade $e$ propaganda. São Paulo: Schoba, 2010.

Artigo submetido: 05/04/2016

Artigo aprovado: 07/06/2015 